\title{
Is Insulin Resistance a Risk Factor for the Progression of Chronic Kidney Disease?
}

\author{
Taner Bastürk $^{\mathrm{a}} \quad$ Abdulkadır Unsal $^{\mathrm{b}}$

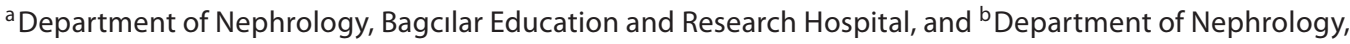 \\ Sisli Etfal Education and Research Hospital, Istanbul, Turkey
}

\section{Key Words}

Insulin resistance $\cdot$ Chronic kidney disease $\cdot$ Hypertension

\begin{abstract}
Background: The aim of this research was to establish whether there is a link between insulin resistance (IR) and glomerular filtration rate (GFR), and assess whether insulinresistant subjects experience a more rapid deterioration in GFR. Methods: We enrolled 73 non-diabetic chronic kidney disease (CKD) stage 2-4 patients. All blood samples were taken after $10 \mathrm{~h}$ of overnight fasting. Fasting blood glucose (FBG), creatinine, uric acid, albumin, cholesterol, triglyceride, insulin, $\mathrm{HbA1c}$, high-sensitivity C-reactive protein (hs-CRP) and intact parathyroid hormone (iPTH) levels as well as proteinuria were analyzed. Patients were followed up for a mean of 30 (24-35) months and renal and metabolic parameters were compared in conjunction with a homeostasis model assessment of IR (HOMA-IR) between the entry and the end of the study period. CKD progression was assessed by recording renal endpoints, which included end-stage renal disease, requiring renal replacement therapy, or overall mortality. Results: The study patients were divided into group 1 ( $n=36)$, without IR, and group $2(n=37)$, with IR. Group 2 patients had a higher FBG $(p=0.003)$ and insulin level $(p=$ 0.001 ) compared to group 1 . The baseline and end of study systolic $(p=0.007)$ and diastolic $(p=0.001)$ blood pressures were decreased in group 1. In group 2, FBG ( $p=0.008), \mathrm{HbA} 1 \mathrm{c}$ $(p=0.009)$, systolic $(p=0.024)$ and diastolic $(p=0.001)$ blood
\end{abstract}

pressures and CRP ( $p=0.047)$ were decreased. In group 2, 8 patients reached renal endpoints while in group 1, 9 patients reached study endpoints. HOMA-IR was not significantly higher among 17 patients who reached the renal endpoint than among the 56 who did not. At baseline, those patients who reached the renal endpoint showed lower GFR ( $p=$ $0.001)$, higher iPTH ( $p=0.004)$ and hs-CRP ( $p=0.002)$ levels. Conclusion: There was no significant difference in GFR at the end of the study between patients who had or did not have IR. Furthermore, HOMA-IR was not significantly different in patients with or without renal endpoints.

Copyright $\odot 2011$ S. Karger AG, Basel

\section{Introduction}

Insulin resistance (IR) in advanced kidney disease has been well recognized since the seminal work by DeFronzo et al. [1] using hyperinsulinemic-euglycemic clamp techniques. IR as well as compensatory hyperinsulinemia are independently associated with an increased prevalence of chronic kidney disease (CKD) $[1,2]$. Hyperinsulinemia has direct renal effects such as induced relaxation of the afferent arteriole, resulting in glomerular hyperfiltration and renal damage. There are many risk factors in the development of diabetic nephropathy. Non-glycemic factors, including genetic susceptibility, lipids and blood pressure, in the pathogenesis of diabetic nephropathy and IR play a central role [3]. High insulin levels stimulate an-

\section{KARGER}

Fax +4161306 1234 E-Mail karger@karger.ch www.karger.com

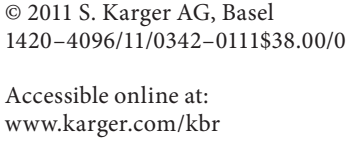

Department of Nephrology, Bagcilar Education and Research Hospital

TR-80650 Istanbul (Turkey)

Tel. +90 212440 4000, Fax +90 2124444000

E-Mail tanerbast@yahoo.com 
giogenesis and mesangial cell proliferation, associated with the development of diabetic nephropathy [4]. IR is thought to play a role in renal damage and kidney disease progression.

The aim of this study was to establish whether there is a link between IR and glomerular filtration rate (GFR), and assess whether insulin-resistant subjects experience a more rapid deterioration in GFR.

\section{Methods}

The study was performed in 73 patients with non-diabetic hypertensive CKD (stages 2-4), between June 2005 and September 2008. CKD patients were divided into two groups - those with and those without IR. The patients were followed up for a mean of 30 (24-35) months.

The exclusion criteria were age $<18$ or $>75$ years, secondary hypertension (disorders of the adrenal gland, including Cushing's syndrome, hyperaldosteronism and pheochromocytoma, drugs such as corticosteroids, non-steroidal anti-inflammatory drugs, sleep apnea, coarctation of the aorta, thyroid problems), diabetes mellitus, previous kidney transplantation, serious systemic disease (systemic lupus erythematosus, periarteritis nodosa, etc.), chronic infections, neoplasmatic diseases or kidney failure (estimated GFR $<15 \mathrm{ml} / \mathrm{min}$ per $1.73 \mathrm{~m}^{2}$ ).

All blood samples were taken after $10 \mathrm{~h}$ of overnight fasting. Fasting blood glucose (FBG), serum creatinine, uric acid, albumin, total cholesterol, triglyceride (TG) insulin, HbAlc, C-reactive protein (hs-CRP) and iPTH levels as well as proteinuria were analyzed. At the same time, blood pressure, weight, and height were measured.

FBG, total cholesterol, TG and albumin were assessed by enzymatic colorimetric assay, serum creatinine by kinetic colorimetric assay, $\mathrm{iPTH}$ levels by solid-phase, two-site chemiluminescent enzyme immunometric method assay on a Immulite automatic analyzer, insulin levels by electrochemiluminescence immunoassay, and hs-CRP by nephelometric assay on an E170 analyzer.

Creatinine clearance was calculated using the CockcroftGault formula: $\mathrm{Ccr}(\mathrm{ml} / \mathrm{min})=(140-$ age $) \times$ measured weight $(\mathrm{kg}) /($ plasma $\mathrm{Cr} \times 72)$. The obtained value was multiplied by 0.85 in women. Body mass index $\left(\mathrm{BMI}=\right.$ weight $\left.(\mathrm{kg}) / \mathrm{height}(\mathrm{m})^{2}\right)$ was obtained from height and weight measurements.

Hypertension was defined as systolic (SBP) and diastolic (DBP) blood pressures of $\geq 140$ and $\geq 90 \mathrm{~mm} \mathrm{Hg}$, respectively, or the use of antihypertensive medications. SBP and DBP were the average of three measurements taken with a brachial sphygmomanometer with the patient in the seated position. Patients were accepted as impaired fasting glucose (IFG): $100 \leq$ IFG $<126 \mathrm{mg} /$ $\mathrm{dl}$, according to the 1997 ADA definition.

Renal function was defined according to the National Kidney Foundation Kidney Disease Outcome Quality Initiative (K/ DOQI) definitions [5], therefore CKDs were defined according to the presence or absence of kidney damage and level of kidney function. Kidney damage was defined as pathologic abnormalities or markers of damage, including abnormalities in blood or urine tests or imaging studies. Among individuals with CKD, the stage was defined by the level of GFR (stages 1-5). Urinary proteinuria concentration was determined by an immunoturbidimetric method. Proteinuria was defined as $\geq 300 \mathrm{mg} /$ day.

IR was assessed by a homeostasis model assessment of IR (HOMA-IR: FBG $(\mathrm{mg} / \mathrm{dl}) \times$ fasting serum insulin level $(\mu \mathrm{U} / \mathrm{l}) /$ 22.5) measured at the beginning of the study. In the present analysis, patients were stratified into two groups according to baseline HOMA-IR ( $\geq 2.5$ ): group 1 had levels below the median of the cohort while group 2 had levels above the median. Patients were followed up for a mean of 30 (24-35) months and renal and metabolic parameters were compared in conjunction with HOMA-IR between the entry and the end of the study period.

CKD progression was assessed by recording renal endpoints, doubling of serum creatinine or a 50\% decrease of GFR end-stage renal disease requiring renal replacement therapy (hemodialysis, peritoneal dialysis or kidney transplantation) or mortality. 32.1\% of our patients received renin-angiotensin system (RAS) blockers, $33.9 \%$ received RAS blockers and calcium channel blockers, $15 \%$ received calcium channel blockers, and $19 \%$ received other antihypertensive drugs ( $\beta$-blockers, $\alpha$-blockers). These drugs were maintained by changing the dosage or a diuretic (loop diuretic) was added throughout the study. Patients who were previously following a low-salt diet maintained it without modification throughout the study.

\section{Statistical Analysis}

Baseline characteristics of study participants are given as frequency (for sex), means \pm SD (for age, BMI, FBG, fasting insulin, LDL and HDL cholesterol) and were compared using two tests, i.e. unpaired Student's t test (two-tailed) for parametric data analysis and the Mann-Whitney test or Wilcoxon test for non-parametric analysis. For research of associated factors, multivariate logistic regression analyses were used. Statistical analyses were performed using the SPSS package (release 15.0).

\section{Results}

Essential hypertension ( $\mathrm{n}=23)$, chronic glomerulonephritis $(n=19)$, polycystic kidney disease $(n=14)$, chronic pyelonephritis $(n=9)$, amyloidosis $(n=5)$ and obstructive nephropathy $(n=3)$ were the causes of CKD among the study patients. Demographic, clinical, and baseline laboratory data are shown in table 1 .

The groups were defined as follows: Group $1(\mathrm{n}=36)$ without IR (21 females, mean age $60 \pm 13$ years, median GFR $40.5 \pm 17 \mathrm{ml} / \mathrm{min}$ per $1.73 \mathrm{~m}^{2}$, BMI $\left.26.9 .7 \pm 4.2\right)$, and group $2(\mathrm{n}=37)$ with IR (17 females, mean age $57 \pm$ 11 years, median GFR $44.4 \pm 21.9 \mathrm{ml} / \mathrm{min}$ per $1.73 \mathrm{~m}^{2}$, BMI $29.3 \pm 7.8$ ). Group 2 patients had a higher FBG $(102.78 \pm 7.92 / 98.28 \pm 8.82 \mathrm{mg} / \mathrm{dl}, \mathrm{p}=0.003)$ and serum insulin level $(15.03 \pm 5.03 / 7.99 \pm 1.89 \mu \mathrm{U} / \mathrm{l}, \mathrm{p}=0.001)$ compared to group 1 , and the other parameters were not significantly different $(\mathrm{p}>0.05)$ (table 2). 12 patients in group 2 had IFG, while no IFG was found in group 1. 
At the end of the study, SBP $(140.36 \pm 16.8 / 129.29 \pm$ $15.37 \mathrm{~mm} \mathrm{Hg}, \mathrm{p}=0.007)$ and DBP $(83.21 \pm 10.2 / 72.14 \pm$ $8.32 \mathrm{~mm} \mathrm{Hg}, \mathrm{p}=0.001)$ were decreased in group 1 . In group 2, FBG $(102.78 \pm 7.92 / 96.48 \pm 11.34 \mathrm{mg} / \mathrm{dl}, \mathrm{p}=$ $0.008)$, HbAlc (5.64 $\pm 0.48 / 5.42 \pm 0.41, \mathrm{p}=0.009)$, SBP $(142.76 \pm 16.88 / 134.83 \pm 14.84 \mathrm{~mm} \mathrm{Hg}, \mathrm{p}=0.024)$ and $\operatorname{DBP}(85.17 \pm 9.86 / 75.86 \pm 7.32 \mathrm{~mm} \mathrm{Hg}, \mathrm{p}=0.001)$ and hs-CRP $(7.95 \pm 6.27 / 5.42 \pm 3.84 \mathrm{mg} / \mathrm{l}, \mathrm{p}<0.047)$ were decreased (table 2). In group 2, 8 of the IFG patients improved, 3 developed diabetes and were treated for type 2 diabetes mellitus, and 8 patients reached renal endpoints (1 died, 7 started dialysis). In group 1, 9 patients reached study endpoints (3 died, 6 started dialysis).

At the end of the study there was a statistically significant difference in GFR between the rest of group 1 ( $\mathrm{n}=$ $27)$ and group $2(\mathrm{n}=29)(46.1 \pm 19.7 / 26.2 \pm 11.6, \mathrm{p}=$ 0.001). HOMA-IR was not significantly higher among 17 patients who reached the renal endpoint than among the 56 who did not. Patients who reached the renal endpoint showed lower GFR $(\mathrm{p}=0.001)$, higher iPTH $(\mathrm{p}=0.004)$ and hs-CRP $(\mathrm{p}=0.002)$ levels (table 3$)$.

\section{Discussion}

We found that there was no significant difference in GFR at the end of the study between patients who had or did not have IR. Furthermore, HOMA-IR was not significantly different in patients with or without renal endpoints. IR per se was not found to be a risk factor for the worsening of renal functions.

DeFronzo et al. [1] used the euglycemic insulin clamp technique in combination with titrated glucose and hepatic venous and femoral venous catheterization to examine the contribution of the liver versus peripheral tissues to the impaired insulin action observed in uremia. They concluded that suppression of hepatic glucose production by physiological hyperinsulinemia was not impaired and that insulin-mediated glucose uptake by the liver was normal in uremic subjects. Tissue insensitivity to insulin is the primary cause of IR in uremia [1].

IR is present in patients with a mild degree of renal dysfunction or even in patients with an apparently normal renal function, i.e. normal creatinine value and low GFR. Thus, kidney disease per se seems to cause an IR syndrome.

The Hiyasama Study found a strong correlation between hyperinsulinemia and renal dysfunction in a study population of 1,065 men and 1,381 women, while a large sample of US adults participating in the Third National
Table 1. Baseline laboratory data of study subjects

$\begin{array}{lc}\text { Age, years } & 58.8 \pm 12.3 \\ \text { Female/male } & 38 / 35 \\ \text { GFR, ml/min } & 42.5 \pm 19.6 \\ \text { BMI } & 28.15 \pm 6.36 \\ \text { FBG, mg/dl } & 101.25 \pm 9.05 \\ \text { HbAlc, \% } & 5.44 \pm 0.39 \\ \text { Serum insulin, } \mu \mathrm{U} / \mathrm{l} & 11.65 \pm 5.72 \\ \text { HOMA-IR } & 2.94 \pm 1.57 \\ \text { SBP, mm Hg } & 142.29 \pm 16.17 \\ \text { DBP, mm Hg } & 85.4 \pm 9.7 \\ \text { Uric acid, mg/dl } & 7.32 \pm 1.96 \\ \text { Albuminemia, g/dl } & 4.21 \pm 0.31 \\ \text { Total cholesterol, mg/dl } & 192.87 \pm 35.27 \\ \text { Serum TG, mg/dl } & 165.9 \pm 101.36 \\ \text { hs-CRP, mg/l } & 8.74 \pm 6.2 \\ \text { iPTH, pg/dl } & 180.37 \pm 163.27 \\ \text { Proteinuria, mg/day } & 580.43 \pm 163.27\end{array}$

Health and Nutrition Examination Survey (NHANES III) showed a strong correlation between the HOMA index, plasma insulin and the risk of CKD [2]. Sit et al. [4] evaluated the prevalence of IR in 89 non-diabetic, nonobese patients with CKD. They reported IR in $48.3 \%$ of their CKD patients. In another study, IR was reported in $50 \%$ of such patients, irrespective of the underlying cause [7-10].

Kobayaski et al. [11] showed that IR is an important risk factor for the progression of renal disease among stage 3 CKD patients who they followed up for at least 3 years. Moreover, Ikee et al. [12] performed a $75 \mathrm{~g}$ oral glucose tolerance test in 23 non-diabetic CKD patients who had renal biopsies. All the vasculature, glomeruli and tubulointerstitial changes in the biopsy were evaluated. IR in particular had an effect on the tubulointerstitial and vascular changes.

Mohteshamzadeh et al. [13] followed up 106 CKD patients for 5 years who were divided into three groups according to their insulin sensitivity. As a result, it was clearly shown that IR is frequent among CKD patients and sometimes progresses to IFG and diabetes mellitus. On the other hand, there was no correlation between IR and GFR [13]. Similarly, Satirapoj et al. [14] demonstrated that IR had a correlation with BMI, TG and arterial blood pressure in CKD patients, but it did not have any correlation with GFR.

In our study, there was no significant difference in GFR at the end of the study in both groups. Moreover, there was no relation between IR and GFR. 12 of those patients with IR initially had IFG and 8 improved, where- 
Table 2. Baseline and end of the study laboratory data of groups 1 and 2

\begin{tabular}{|c|c|c|c|c|c|c|}
\hline & Group $1^{\mathrm{a}}(\mathrm{n}=36)$ & Group $1^{\mathrm{b}}(\mathrm{n}=28)$ & $\mathrm{p}$ & Group $2^{\mathrm{a}}(\mathrm{n}=37)$ & Group $2^{\mathrm{b}}(\mathrm{n}=28)$ & $\mathrm{p}$ \\
\hline $\mathrm{GFR}, \mathrm{ml} / \mathrm{min}$ & $40.5 \pm 17$ & $46.1 \pm 19.7$ & NS & $44.4 \pm 21.9$ & $48.6 \pm 21.2$ & NS \\
\hline $\mathrm{BMI}$ & $26.9 \pm 4.1$ & $28.5 \pm 3.4$ & NS & $29.3 \pm 7.8$ & $28.2 \pm 4.4$ & NS \\
\hline FBG, mg/dl & $98.2 \pm 8.8$ & $95.4 \pm 10$ & NS & $102.7 \pm 7.9$ & $96.4 \pm 11.3$ & 0.008 \\
\hline Serum insulin, $\mu U / 1$ & $7.7 \pm 1.8$ & $7.9 \pm 1.9$ & NS & $15 \pm 5.03$ & $15.6 \pm 8.8$ & NS \\
\hline HOMA-IR & $1.85 \pm 0.4$ & $1.86 \pm 0.9$ & NS & $3.98 \pm 1.5$ & $3.77 \pm 2$ & NS \\
\hline $\mathrm{HbA} 1 \mathrm{c}, \%$ & $5.4 \pm 0.39$ & $5.5 \pm 0.46$ & NS & $5.6 \pm 0.48$ & $5.42 \pm 0.41$ & 0.009 \\
\hline $\mathrm{SBP}, \mathrm{mm} \mathrm{Hg}$ & $140.3 \pm 16.8$ & $129.3 \pm 15.3$ & 0.007 & $142.6 \pm 15.3$ & $134.8 \pm 14.8$ & 0.024 \\
\hline $\mathrm{DBP}, \mathrm{mm} \mathrm{Hg}$ & $83.2 \pm 10.2$ & $72.1 \pm 8.3$ & 0.001 & $85.17 \pm 9.8$ & $75.8 \pm 7.5$ & 0.001 \\
\hline Uric acid, mg/dl & $7.6 \pm 1.9$ & $6.9 \pm 2.1$ & NS & $7.05 \pm 2.1$ & $6.76 \pm 2.1$ & NS \\
\hline Albuminemia, g/dl & $4.1 \pm 0.3$ & $4.2 \pm 0.2$ & NS & $4.2 \pm 0.3$ & $4.2 \pm 0.2$ & NS \\
\hline Total cholesterol, mg/dl & $194.6 \pm 24.8$ & $198.4 \pm 40.1$ & NS & $192.4 \pm 43.2$ & $201.2 \pm 48.1$ & NS \\
\hline Serum TG, mg/dl & $154.8 \pm 80$ & $170.2 \pm 78$ & NS & $172.9 \pm 128$ & $159.8 \pm 73$ & NS \\
\hline hs-CRP, mg/l & $7.9 \pm 6.7$ & $8.6 \pm 10.5$ & NS & $7.9 \pm 6.2$ & $5.4 \pm 3.8$ & 0.047 \\
\hline iPTH, pg/dl & $165 \pm 115$ & $141 \pm 114$ & NS & $198 \pm 223$ & $120 \pm 84$ & NS \\
\hline Proteinuria, mg/day & $650.2 \pm 869$ & $454.9 \pm 553$ & NS & $542.6 \pm 660$ & $309.6 \pm 218$ & NS \\
\hline
\end{tabular}

${ }^{a}$ Baseline study laboratory data of the two groups. ${ }^{b}$ End of study laboratory data of the two groups.

Table 3. Patients who did or did not reach renal endpoint (RE) laboratory data

\begin{tabular}{lccl}
\hline & $\begin{array}{l}\text { Reached RE } \\
(\mathrm{n}=56)\end{array}$ & $\begin{array}{l}\text { Did not reach RE } \\
(\mathrm{n}=17)\end{array}$ & $\mathrm{p}$ \\
\hline GFR, ml/min & $46.1 \pm 19.7$ & $26.2 \pm 11.6$ & 0.001 \\
BMI & $28.1 \pm 6.6$ & $28 \pm 5.2$ & $\mathrm{NS}$ \\
FBG, mg/dl & $100.68 \pm 8.64$ & $103.14 \pm 10.44$ & $\mathrm{NS}$ \\
Serum insulin, $\mu \mathrm{U} / \mathrm{l}$ & $11.3 \pm 5.5$ & $11.3 \pm 7.4$ & $\mathrm{NS}$ \\
HOMA-IR & $2.83 \pm 1.5$ & $2.94 \pm 1.9$ & $\mathrm{NS}$ \\
SBP, mm Hg & $141.7 \pm 16.9$ & $144.1 \pm 13.7$ & $\mathrm{NS}$ \\
DBP, mm Hg & $84.5 \pm 10.2$ & $88.2 \pm 8.1$ & $\mathrm{NS}$ \\
hs-CRP, mg/l & $7.5 \pm 6.4$ & $12.7 \pm 5.4$ & 0.002 \\
iPTH, pg/dl & $148.2 \pm 138$ & $288 \pm 247$ & 0.004 \\
\hline
\end{tabular}

as 3 progressed to overt diabetes. Carbohydrate metabolism disorders may be found in patients who have CKD, therefore this group of patients should be screened for diabetes. Those patients reaching renal endpoints had low GFR, high iPTH and hs-CRP levels. They did not demonstrate a statistically significant difference in terms of HOMA-IR. Furthermore, $22.2 \%$ of IR patients and $24.3 \%$ of non-IR patients progressed to endpoints. IR per se was not found to be a risk factor for worsening of renal functions.

IR is frequently observed in patients with essential hypertension, and the RAS has been demonstrated to modulate the status of IR. Arterial hypertension is frequently present in patients with CKD, consequently antihypertensive drugs are commonly used in these patients. However, not all of them exert similar effects on metabolic alterations that are observed in these patients. Diuretics are associated with hyperinsulinemia, hyperglycemia, and increased IR in renal patients, whereas ACEI and angiotensin II receptor antagonists are the ones that have been shown to improve insulin sensitivity. This improvement in insulin sensitivity that is achieved with RAS blockers has been related to a decreased incidence of newonset type 2 diabetes [15-18].

De Vinuesa et al. [19] demonstrated that patients with moderate CKD have a high prevalence of IR, and that the administration of the ARB olmesartan improves glucose metabolism and insulin sensitivity. $66 \%$ of our patients received RAS blockers. Baseline and the end of the study data revealed that $\mathrm{SBP}$ and $\mathrm{DBP}$, proteinuria, FBG and HbAlc were decreased. HOMA-IR and GFR did not reveal any significant changes.

\section{Conclusions}

There was no significant difference in GFR at the end of the study between patients who had or did not have IR. Furthermore, HOMA-IR was not significantly different in patients with or without renal endpoints. IR per se was not found to be a risk factor for the worsening of renal functions. 


\section{References}

1 DeFronzo RA, Alvestrand A, Smith D, Hendler R, Hendler E, Wahren J: Insulin resistance in uremia. J Clin Invest 1981;67:563568.

$\checkmark 2$ Chen J, Muntner P, Hamm LL, Fonseca V, Batuman V, Whelton PK, He J: Insulin resistance and risk of chronic kidney disease in nondiabetic US adults. J Am Soc Nephrol 2003;14:469-477.

3 Orchard TJ, Chang YF, Ferrell RE, Petro N, Ellis DE: Nephropathy in type 1 diabetes: a manifestation of insulin resistance and multiple genetic susceptibilities? Further evidence from the Pittsburgh Epidemiology of Diabetes Complication Study. Kidney Int 2002;62:963-970.

$\checkmark 4$ Knight SF, Imig JD: Obesity, insulin resistance, and renal function. Microcirculation 2007; 14:349-362.

$\checkmark 5$ National Kidney Foundation (K/DOQI): Clinical practice guidelines for chronic kidney disease: evaluation, classification and stratification. Am J Kidney Dis 2002;39:S1S266.

$\checkmark 6$ Sit D, Kadiroglu AK, Kayabasi H, Yilmaz ME: The prevalence of insulin resistance in nondiabetic nonobese patients with chronic kidney disease. Adv Ther 2006;23:988-998.

$\checkmark 7$ Kubo M, Kiyohara Y, Kato I, et al: Effect of hyperinsulinaemia on renal function in a general Japanese population - The Hiyasama Study. Kidney Int 1999;55:2450-2456.
8 Vareesangthip K, Tong $\mathrm{P}$, Wilkinson R, Thomas TH: Insulin resistance in adult polycystic kidney disease. Kidney Int 1997;52: 503-508.

9 Fliser D, Pacini G, Engelleiter R, KautzkyWiller A, Prager R, Franek E, Titz E: Insulin resistance and hyperinsulinemia are already present in patients with incipient renal disease. Kidney Int 1998;53:1343-1347.

10 Hjelmesaeth J, Hartmann A: Insulin resistance in patients with adult polycystic kidney disease. Nephrol Dialysis Transplant 1999; 14:2521-2522.

11 Kobayashi H, Tokudome G, Hara Y, Sugano N, Endo S, Suetsugu Y, Kuriyama S, Hosoya $\mathrm{T}$ : Insulin resistance is a risk factor for the progression of chronic kidney disease. Clin Nephrol 2009;71:643-651.

-12 Ikee R, Hamasaki Y, Oka M, Maesato K, Mano T, Moriya H, Ohtake T, Kobayashi S: Glucose metabolism, insulin resistance, and renal pathology in non-diabetic chronic kidney disease. Nephron Clin Pract 2008 108:c163-c168.

13 Mohteshamzadeh M, Wong C, Whiticar R, Thomas S: Is there a link between insulin resistance and chronic kidney disease in men with treated hypertension? Analysis of 5-year data. Am J Nephrol 2009;29:116-122.

14 Satirapoj B, Supasyndh O, Boonyavarakul A, Luesutthiviboon L, Choovichian P: The correlation of insulin resistance and renal function in non-diabetic chronic kidney disease patients. J Med Assoc Thai 2005;883:S97S104.
5 Yildiz A, Hursit M, Celik AV, Kayacan SM, Yazici H, Akkaya V, Gu AO, Karsidag K: Doxazosin but not amlodipine decrease insulin resistance in patients with chronic renal failure: a prospective, randomized controlled study. Clin Nephrol 2002;58:405410 .

16 Becker B, Kronenberg F, Kielstein JT, Haller $\mathrm{H}$, Morath C, Ritz E, Fliser D, for the MMKD Study: Insulin resistance syndrome, adiponectin and vascular events in patients with kidney disease: the mild and moderate kidney disease study. J Am Soc Nephrol 2005;16: 1091-1098

17 Benson SC, Perhadsingh HA, Ho CI, Chittiboyina A, Desai P, Pravenec M, Qi N, Wang J, Avery MA, Kurtz TW: Identification of telmisartan as a unique angiotensin II receptor antagonist with selective PPAR- $\gamma$ modulating activity. Hypertension 2004;43:9931002

18 Matayoshi T, Kamide K, Takiuchi S, et al: Relationship between insulin resistance and the renin-angiotensin system: analysis for patients with essential and renovascular hypertension. Clin Exp Hypertens 2007;29: 479-487.

19 De Vinuesa SG, Goicoechea M, Kanter J, et al: Insulin resistance, inflammatory biomarkers, and adipokines in patients with chronic kidney disease: effects of angiotensin II blockade. J Am Soc Nephrol 2006; 17(suppl 3):S206-S212. 